\title{
Cks1 proteasomal turnover is a predominant mode of regulation in breast cancer cells: Role of key tyrosines and lysines
}

\author{
VINAYAK KHATTAR $^{1}$ and JAIDEEP V. THOTTASSERY ${ }^{1,2}$ \\ ${ }^{1}$ Southern Research Institute; ${ }^{2}$ UAB Comprehensive Cancer Center, Birmingham, AL, USA
}

Received August 29, 2014; Accepted October 1, 2014

DOI: $10.3892 /$ ijo.2014.2728

\begin{abstract}
Constitutive levels of Cks1 protein are very high in mammary carcinoma tissue and in breast tumor cell lines. However, despite being transcribed at relatively high levels, Cks1 protein is very low in normal mammary tissue. Also, basal Cks1 is barely detectable in primary human mammary epithelial cells (HMECs). Epoximicin, a proteasome inhibitor, induced detectable endogenous Cks1 in HMECs, and upregulated it above the basal level in MCF-7 breast cancer cells. Interestingly, transiently transfected Cks1 is remarkably unstable and accumulates only upon proteasomal blockade in multiple cell lines even when driven by the strong CMV promoter-enhancer. We examined the stability of site-directed Cks1 mutants in order to identify the structural determinants of its turnover in cancer cells. Since protein turnover is regulated by phosphorylation, and phosphoproteomic studies reveal phosphorylated tyrosines in Cks1, we replaced its five conserved tyrosines $(\mathrm{Y})$ with phenylalanine $(\mathrm{F})$, both individually and in combinations. We find that like wild-type, all transiently transfected mutant Cks1 vectors, even when driven by the CMV promoter-enhancer, expressed detectable protein only in cells treated with epoximicin. However, turnover of the Y8F, Y12F and Y19F Cks1 mutants was more rapid than that of wild-type, Y7F and Y57F. Since lysines are modified by ubiquitination or acetylation we also examined the consequences of lysine to arginine (K-R) substitutions on Cks1 proteasomal turnover. We found that the individual mutations K4R, K26R, K30R, and K34R slowed Cks1 turnover, while the K79R mutation or the combined mutation K75-76-78-79R increased turnover. Taken together, regulation of $\mathrm{Cks} 1$ protein stability is crucially dependent on specific tyrosine and lysine residues which are potential sites for post-translational modifications.
\end{abstract}

Correspondence to: Dr Jaideep Thottassery, Biochemistry and Molecular Biology Department, Drug Discovery Division, Southern Research Institute, 2000 Ninth Ave South, Birmingham, AL 35205, USA

E-mail: jthottassery@hotmail.com

Key words: Cks1, Cks2, Skp2, p27 ${ }^{\mathrm{Kip} 1}, \mathrm{p} 130 / \mathrm{Rb} 2, \mathrm{SCF}$ ubiquitin ligase, proteasome

\section{Introduction}

Cyclin kinase subunit 1 (Cks1), an evolutionarily conserved 9-kDa protein first identified as a component of cyclin-Cdk complexes, has been implicated in cell cycle progression, transcriptional regulation, and growth signaling pathways (1). While many of its molecular mechanisms are still an enigma, one well characterized biochemical mechanism in mammalian cells is its role as an essential adaptor in the ubiquitination of the tumor suppressor $\mathrm{p} 27^{\mathrm{Kip} 1}$ by the SCF-Skp2 ubiquitin ligase $(2,3)$. Multiple roles for Cks1 that are independent of Skp2$\mathrm{p} 27^{\mathrm{Kip} 1}$ have also been recognized in mammalian cells $(1,4-6)$. Studies from our laboratory and others taken collectively indicate that markedly high Cks1 protein levels are present in a majority of cancers and are correlated to tumor aggressiveness and dissemination (7-13). Whole transcriptome sequencing (RNA-Seq) has also revealed that Cks1 is well transcribed in normal breast epithelium obtained from human breast tissue (14). However, despite the fact that its mRNA is expressed, Cks1 protein is nearly undetectable in normal tissues $(4,7)$. These findings suggested that a predominant mode of regulation of Cks1 is at the level of the protein.

In our previous studies we had shown that normal mouse or rat tissues exhibit very low levels of Cks1 protein, whereas its levels were very high in mammary tumors excised from murine transgenic models of mammary tumorigenesis (erbB2, c-myc and polyoma middle-T transgenic mice) and also in a carcinogen-initiated rat mammary tumor (7). A previous report from our laboratory also indicated that $\mathrm{Cks} 1$ protein although nearly undetectable in primary human mammary epithelial cells (HMECs) was transiently induced when stimulated with medium containing insulin, epidermal growth factor (EGF) and hydrocortisone (4). Thus, timely downregulation of Cks1 protein, after it has served its purpose, appears to be important in normal tissues. Despite these findings, and the above mentioned studies from other groups that demonstrate markedly high Cks1 levels in cancer, very little is known about the mechanisms that regulate $\mathrm{Cks1}$ protein turnover in tumor cells. The vast majority of intracellular proteins are degraded by the ubiquitin proteasome system (UPS) (15). However, though Cks1 is known to be ubiquitinated, the mechanisms involved in this process and its subsequent proteasomal turnover are unknown $(16,17)$. Also, no 'degrons' or structural determinants of protein degradation have been found in Cks1 except for a minimal portion of the canonical D-box found 
in substrates of APC/C ubiquitin ligase (17). However, the relevance of this 'minimal D-box' is uncertain since Cks1 does not appear to be a direct target of the APC/C ubiquitin ligase (17).

It is now well recognized that cells utilize phosphorylation and dephosphosphorylation of specific tyrosines, serines or threonines, as a means of regulating the ubiquitination of proteins, which serves as a tag for subsequent proteasomal degradation (18-22). Phosphorylation has been suggested to both enhance the stability of proteins in some cases, and increase degradation in others (19-22). Phosphoproteomic studies with cancer cells have demonstrated that Cks1 is phosphorylated on tyrosine (Y) residues. Cks1 is an evolutionarily conserved protein with four out of its five $\mathrm{Y}$ residues conserved across species as diverse as yeast, the fruit fly, C. elegans and vertebrates. Phosphoproteomic studies have revealed that Cks1 is phosphorylated on Y8 in a T-cell leukemia cell line and also in an immortalized HMEC line transfected with the HER2 tyrosine kinase $(23,24)$. Cks1 has also been found to be phosphorylated on Y19 in cells expressing the NPM-ALK tyrosine kinase (25). Furthermore, the Y57 residue in Cks1 has also been found to be phosphorylated in the HeLa cervical carcinoma line (26). These findings suggested that there might be a potential role for post-translational modification of specific $\mathrm{Y}$ residues in regulating Cks1 protein turnover. Moreover, Shirayama and coworkers have identified a naturally occurring $\mathrm{Y}$ to $\mathrm{F}$ (phenylalanine) mutant in C. elegans that corresponds to the $\mathrm{Y} 8$ residue in human Cks1 that resulted in cell polarity defects in this organism during the course of development (27). Although whether this 'non-phosphorylatable' mutant exhibited alterations in stability was not examined, structural analysis of wild-type Cks1 has suggested that four of the five $Y$ residues within Cks family of proteins (including Y8) are exposed to the solvent in the monomeric form of the protein but are sequestered towards the interior of the protein in dimeric state (28). Since Cks1 switches between these two native states, regulation of this conformational switching could allow or preclude access of these residues to kinases, phosphatases and other proteins that physically interact with Y-containing motifs leading to modulation of its stability and function.

Considerable cross-talk has also been demonstrated between ubiquitination and/or acetylation on lysine $(\mathrm{K})$ residues and Y-phosphorylation $(29,30)$. There are nine $\mathrm{K}$ residues in Cks1 of which four including K11, K26, K30 and K34 are conserved across multiple species. To investigate the role of specific Ys and Ks in the degradation of Cks1 we have generated single and multiple Y-to-F and K-to-R changes. We demonstrate that mutant Cks1 with specific altered $\mathrm{Y}$ residues (Y8F, Y12F and Y19F) exhibited markedly increased proteasomal turnover. In contrast, the K4R, K26R, K30R, and K34R Cks1 mutants exhibited markedly slowed turnover relative to wild-type (WT). Interestingly, mutating the terminal K79 in Cks1, or combined replacement of its four C-terminal Ks (K75, 76, 78 and 79) with Rs, markedly increased its proteasomal turnover. Our results support the notion that Cks1 protein stability is crucially dependent on distinct tyrosine and lysine residues which are potential sites for post-translational modifications that could regulate its turnover.

\section{Materials and methods}

Cell lines and chemicals. MCF-7, T-47-D, BT-474, PC-3 and 293 cell lines were obtained from American Type Culture Collection (Manassas, VA, USA) and maintained in RPMI media obtained from Thermo Fisher Scientific (Waltham, MA, USA, Cat no. SH-30027) containing 10\% fetal bovine serum (FBS) and $100 \mathrm{U} / \mathrm{ml}$ penicillin-streptomycin antibiotic solution (from Life Technologies, Grand Island, NY, USA, Cat no. 15140122). HMECs were from Lonza (Allendale, NJ, USA, Cat no. CC-2551) and HMEC 184A1 cells (a carcinogen immortalized clone of HMEC) was a gift from Dr Steven Wiley (Pacific Northwest Labs, Richland, WA, USA) were maintained in mammary epithelial growth medium (MEGM, from Lonza, Cat no. CC-3150) which contains human epidermal growth factor, insulin, and hydrocortisone. All cells were maintained at $5 \% \mathrm{CO}_{2}$ and $37^{\circ} \mathrm{C}$. $\beta$-clasto-lactacystin was obtained from Boston Biochem (Cambridge, MA, USA, Cat no. I-100), MG-132 was from SelleckChem (Houston, TX, USA, Cat no. S-2619), epoximicin was from Apex Bio, (Houston, TX, USA, Cat no. A2606), and cycloheximide was from Sigma-Aldrich (St. Louis, MO, USA, Cat no. C7698).

Cloning and site-directed mutagenesis of $C k s 1$.Epitope-tagged wild-type human Cks1 expression plasmids (pIIB-CMV-HACks1, pIIB-CMV-FLAG-Cks1 and pIIB-CMV-FLAG-Cks2) were constructed using a vector containing the strong CMV promoter-enhancer previously described by us (7). An additional HA-Cks1 expression plasmid was constructed by ligating a PCR generated HA-Cks1 fragment with BamHI and NotI overhangs into the pcDNA3 vector. The QuikChange ${ }^{\mathrm{TM}}$ kit from Agilent Technologies (Santa Clara, CA, USA, Cat no. 210518) was employed to generate all the Y-F, Y-E and K-R mutants of Cks1. pIIB-CMV-HA-Cks1 plasmid was used as the template for these site directed mutagenesis reactions. Briefly, mutagenic primers were employed to introduce single nucleotide changes within the $\mathrm{Y}$ or $\mathrm{K}$ codons present in the Cks1 coding region. All constructs were sequenced and verified to confirm the location and identity of the substitution.

Transfection of Cksl expressing plasmids. In general, cells were plated in 6-cm UltraCruz ${ }^{\mathrm{TM}}$ tissue culture dishes (from Santa Cruz, Dallas, TX, USA, Cat no. 351863) at density of 0.6-1 million cells to achieve a confluence of 30-50\% on the day of transfection. Cells were transfected using Lipofectamine ${ }^{\mathrm{TM}}$ (Life Technologies, Cat no. 18324-012) according to the manufacturer's instructions. Briefly, 3-4 $\mu \mathrm{g}$ of DNA was complexed with 10-12 $\mu 1$ of Lipofectamine in serum-free OptiMEM $^{\mathrm{TM}}$ medium (Life Technologies, Cat no. 31985-070). DNA-Lipofectamine complexes were added to the cells and incubated in serum-free medium for $16 \mathrm{~h}$. The medium was then replaced with RPMI medium containing 10\% FBS for $20 \mathrm{~h}$. Epoximicin was added to the cells as indicated in the text. To ensure equal input for each transfection DNA concentration of each plasmid preparation was measured and normalized to a concentration of $1 \mu \mathrm{g} / \mathrm{ml}$. Transfection efficiency was assessed by measuring exogenous Cks1 gene expression by a custom TaqMan $^{\text {TM }}$ probe (see Real-time quantitative PCR) designed to detect only the exogenous HA-tagged Cks1 mRNA. Exogenous 
Cks1 protein was assessed by immunoblotting with anti-HA antibody.

Cycloheximide (Chx) chase experiments. To assess the turnover of endogenous Cks1, de novo protein synthesis was blocked by adding Chx to cells and then assessing the turnover of the Cks1 protein in the presence or absence of proteasomal inhibitors. MCF-7 cells were pretreated with epoximicin for $30 \mathrm{~min}$. Following this the cells were briefly washed with $1 \mathrm{X}$ phosphate buffered saline and were exposed to $\mathrm{Chx}$ in presence or absence of epoximicin. Cells were then harvested at regular intervals and protein lysates from these cells were subjected to immunoblotting with anti-Cks1 antibody. To compare the turnover of WT and mutant Cks1 protein, pIIBCMV-HA-Cks1 WT plasmid or the plasmids bearing Y-F, Y-E or K-R transfection were transfected into MCF-7 cells as described above (see transfection of WT and mutant Cks1). Chx chase experiments were carried out as described above. Immunoblotting was done with an anti-HA antibody to compare the turnover of mutant and WT Cks1 proteins over time.

Ubiquitination assays. A HA-ubiquitin plasmid (obtained from Dr Harish Ramanathan, NIH, Bethesda, MD, USA) was transfected into MCF-7 as described above. Cells were then treated with proteasomal inhibitors for $8 \mathrm{~h}$ and harvested. Protein lysate (100-200 $\mu \mathrm{g}$ ) from the harvested cells was subjected to immunoprecipitation (IP) with 1-2 $\mu \mathrm{g}$ of Cks1 antibody using the Exacta Cruz ${ }^{\mathrm{TM}}$ F kit (from Santa Cruz, Cat no. 45043) according to the manufacturer's instructions. Normal rabbit IgG serum (Santa Cruz, Cat no. 2027) was used as an isotype control for non specific binding during IP experiments. The IPs were then transferred to nitrocellulose membranes by overnight wet transfer and subjected to immunoblotting as described below to assess changes in ubiquitinated Cks1.

Real-time quantitative PCR. Total RNA was isolated from cells using the TRI reagent obtained from Molecular Research Center (Cincinnati, OH, USA, Cat no. TR118) according to the manufacturer's protocol. The samples were then treated with amplification grade DNAse (from Life Technologies, Cat no. 18068-015) to remove genomic DNA contamination. DNAse was inactivated by heating at $65^{\circ} \mathrm{C}$ for $20 \mathrm{~min}$ in the presence of $1 \mathrm{mM}$ EDTA. First-strand cDNA was synthesized using the iScript ${ }^{\mathrm{TM}}$ kit (from Bio-Rad, Hercules, CA, USA, Cat no. 170-8891). TaqMan ${ }^{\mathrm{TM}}$ gene expression assays from Life Technologies were employed to measure endogenous Cks1 (Cat no. 4331182, gene ID: Hs02518862_g1) and GAPDH (Cat no. 4331182, gene ID: Hs99999905_m1) transcript levels. The reactions were carried out in Chromo4 ${ }^{\mathrm{TM}}$ Continuous Fluorescence Detector (from Bio-Rad) using the following cycling conditions: 40 cycles of $20 \mathrm{sec}$ each at $95^{\circ} \mathrm{C}$ and $1 \mathrm{~min}$ at $60^{\circ} \mathrm{C}$. The comparative $\mathrm{CT}$ method was used to represent the relative expression level of Cks1. A custom TaqMan probe designed to detect only the HA-tagged Cks1 mRNA was employed to determine transfection efficiency. The relative expression level is expressed as a unitless number and calculated as $2^{-\triangle \Delta C T}$ as previously described (31).

In vitro translation of WT and mutant Cksl proteins. To assess the rate of translation for WT and mutant Cks1, a kit for in vitro expression of Cks1 from (Thermo Fisher Scientific Cat no. 88881) was employed. WT and mutant Cks1 constructs (described above) were excised from the pIIB-CMV-HA-Cks1 backbone and ligated under a T7 promoter into the pT7CFE vector. This system allows robust in vitro expression of the WT or the mutant Cks1 protein in HeLa cell lysates. Following priming of the lysates, with the T7 expressing Cks1 construct, an energy source, and a translation-transcription mix containing accessory proteins and cofactors to drive in vitro synthesis of the proteins, aliquots were taken at regular intervals. The aliquots were then electrophoresed on SDS-PAGE gels and immunoblotted with anti-HA antibodies to assess the rate of synthesis of WT and the mutant proteins.

Immunoblotting. Cells harvested following each experiment were lysed with 1X lysis buffer from Cell Signaling (Danvers, MA, USA, Cat no. 9803). Lysates (25-40 $\mu \mathrm{g})$ were run on Mini-PROTEAN ${ }^{\mathrm{TM}}$ or Criterion ${ }^{\mathrm{TM}}$ gels (Bio-Rad) and transferred on to nitrocellulose membranes by overnight wet transfer. The membranes were blocked for $1 \mathrm{~h}$ with $5 \%$ milk in $0.05 \%$ TBST and probed with the following antibodies: anti-Cks1 (Life Technologies, Cat no. 366-800, 1:500-1:2,000), anti-HA Clone-6E2 (Cell Signaling Technology, Cat no. 2367, 1:2,000-1:3,000), anti-FLAG Clone-M2 (Sigma, St. Louis, MO, USA, F1804, 1:500-1:1,000), anti-His (Thermo Fischer, Cat no. MA1-21315) and anti-GAPDH Clone-14C10 (Cell Signaling Technology, Cat no. 2118, 1:20,000-1:50,000). The membranes were then washed with $1 \mathrm{X}$ TBST three times, $5 \mathrm{~min}$ each, and probed with appropriate HRP-tagged secondary antibodies for $1 \mathrm{~h}$. Supersignal ${ }^{\mathrm{TM}}$ West Pico enhanced chemiluminescence kit was used (from Thermo Fisher, Cat no. 34080) for imaging. Image acquisition was done using the LAS Image Quant $^{\mathrm{TM}} 4010$ system (from GE Healthcare, Waukesha, WI, USA).

\section{Results}

Breast cancer cell lines exhibit high Cks 1 protein levels unlike primary HMECs. We have previously shown that mammary tumors excised from transgenic models of mammary tumorigenesis and carcinogen initiated rat mammary tumors have very high levels of Cks1 protein in comparison to normal mammary glands, in which the Cks1 protein was nearly undetectable (7). This analysis was extended by comparing relative Cks1 protein levels in primary HMECs, HMEC 184A1 and the breast carcinoma cell lines MCF-7, T47D and BT-474 (Fig. 1A). Immunoblot analysis revealed that primary HMECs, similarly to normal mammary glands, did not have detectable Cks1 protein (Fig. 1A). Interestingly HMEC 184A1, a carcinogen immortalized HMEC line did exhibit a modest level of Cks1 protein, although even in this line the Cks1 protein was substantially less as compared to that in the breast cancer cell lines (Fig. 1A). In the breast cancer lines, Cks1 levels were comparable in the MCF-7 and BT-474 lines while the levels in T-47D were somewhat higher (Fig. 1A).

We next compared Cks1 mRNA levels in the HMEC lines versus the three breast cancer lines. Interestingly, despite displaying no detectable protein there was significant Cks1 mRNA in HMEC which was comparable to that in the breast cancer lines MCF-7 and BT-474 (Fig. 1B). Indeed, the 
A

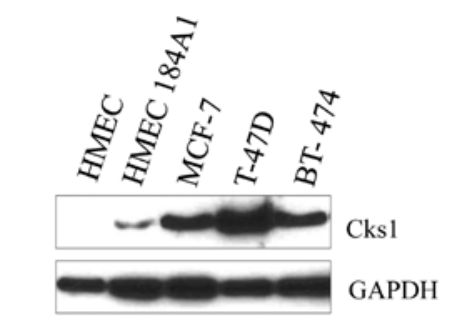

B

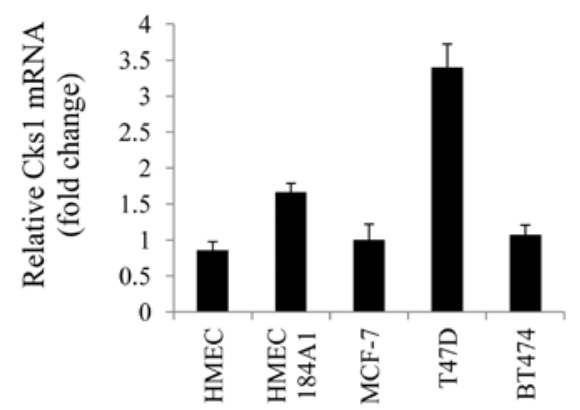

C

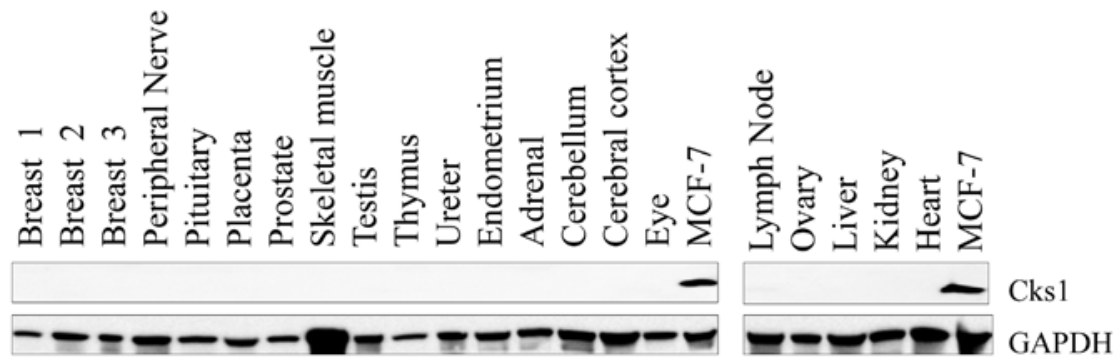

Figure 1. Cks1 protein levels are very high in breast cancer cell lines unlike primary HMECs. (A) Protein lysates from HMECs, carcinogen immortalized HMECs (HMEC 184A1) and three different breast cancer cell lines were examined for Cks1 protein expression by immunoblotting. (B) qRT-PCR analysis of Cks1 gene expression for cell lines shown in (A). Values represent mean \pm SEM of three independent experiments. (C) Cks1 protein levels are undetectable in a panel of normal human tissues. Lysates from indicated human tissues and the MCF-7 breast carcinoma line were examined for Cks1 protein by immunoblotting.

immortalized HMEC line 184A1, which also had very low protein levels, expressed even more Cks1 mRNA than the MCF-7 line (Fig. 1B). These results indicate that, in general, Cks1 mRNA expression does not correlate with protein levels suggesting that a major component of its regulation could be at the translational or post-translational level. These data are also in agreement with similar findings from analysis of datasets from the Oncomine ${ }^{\mathrm{TM}}$ database wherein transcript levels of Cks1 were found to be largely similar between normal breast tissues and ductal breast carcinomas in a number of studies (not shown). Immunoblot analysis also revealed that Cks1 protein was not detectable in a panel of lysates from several normal human tissues as well as three separate lysates from normal breast (Fig. 1C).

Cksl is degraded by the proteasome in primary HMECs and in breast cancer cells. Cks1 protein turnover is known to be regulated by the UPS pathway in the 293 and HeLa cell lines $(16,17)$. We surmised therefore that the marked differences in Cks1 protein observed between HMECs and MCF-7 may be due to differences in its rate of proteasomal degradation in these cell types. To test this we first compared Cks1 protein levels in parallel time course experiments where both HMECs and MCF-7 cells were treated with the proteasomal inhibitor epoximicin $(0.5 \mu \mathrm{M})$ (Fig. $2 \mathrm{~A}$ and B). Our results indicate a time-dependent stabilization of Cks1 protein levels in HMECs and in MCF-7 when treated with epoximicin. Because of the high basal levels of Cks1 in MCF-7 cells stabilization was only noticeable when the western blots were exposed to film for short periods (Fig. 2B). We also observed that Cks1 mRNA was not altered following epoximicin treatment, confirming that the Cks1 increases exhibited by both cell types was indeed due to blockade of proteasomal degradation and not due to alterations in its message (Fig. 2B). As in the case of MCF-7, Cks1 protein stabilization after epoximicin treatment was also observed in T47D breast carcinoma cells and in the $\mathrm{PC}-3$ prostate carcinoma cell line, indicating that $\mathrm{Cks} 1$ is regulated through the proteasomal degradation pathway in multiple cancer cell types (Fig. 2C). However, given high basal Cks1 levels in cancer cells in general, further stabilization by proteasomal blocakade is relatively modest (Fig. 2C).

We next assessed the effects of proteasomal inhibition on the constitutive turnover kinetics of $\mathrm{Cks} 1$ in MCF-7 cells after blocking translation with cycloheximide (Chx). We observed that Cks1 was markedly depleted in MCF-7 but only after $\sim 8 \mathrm{~h}$ of Chx treatment (Fig. 2D). Epoximicin significantly blocked Cks1 depletion in the presence of Chx (Fig. 2D). Of note, Cks1 protein was still present $16 \mathrm{~h}$ after $\mathrm{Chx}$ treatment in the absence of epoximicin, suggesting that Cks1 is considerably stable in carcinoma cells. Nonetheless, the fact that it is stabilized further by epoximicin suggests that concomitant degradation by the proteasomal pathway, even in cancer cells, is a predominant regulator of steady-state Cks1 levels (Fig. 2D).

Proteasome inhibition stabilizes ubiquitinated Cksl in MCF-7 breast cancer cells. Ubiquitin ligation to either the $\varepsilon$-amino group of lysines or the amino terminus of a protein can serve as a tag to direct proteins to degradation by the $26 \mathrm{~S}$ proteasome. To test whether Cks1 in MCF-7 cells is ubiquitinated 
A

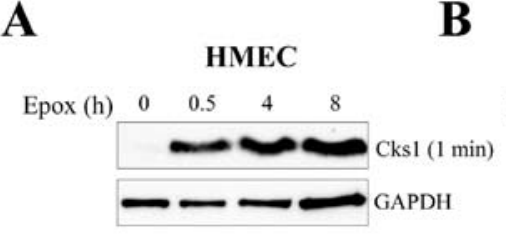

C

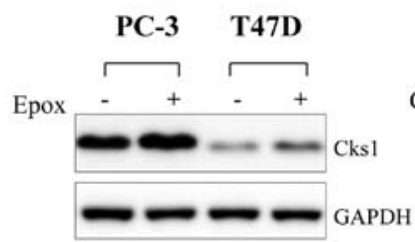

B

D
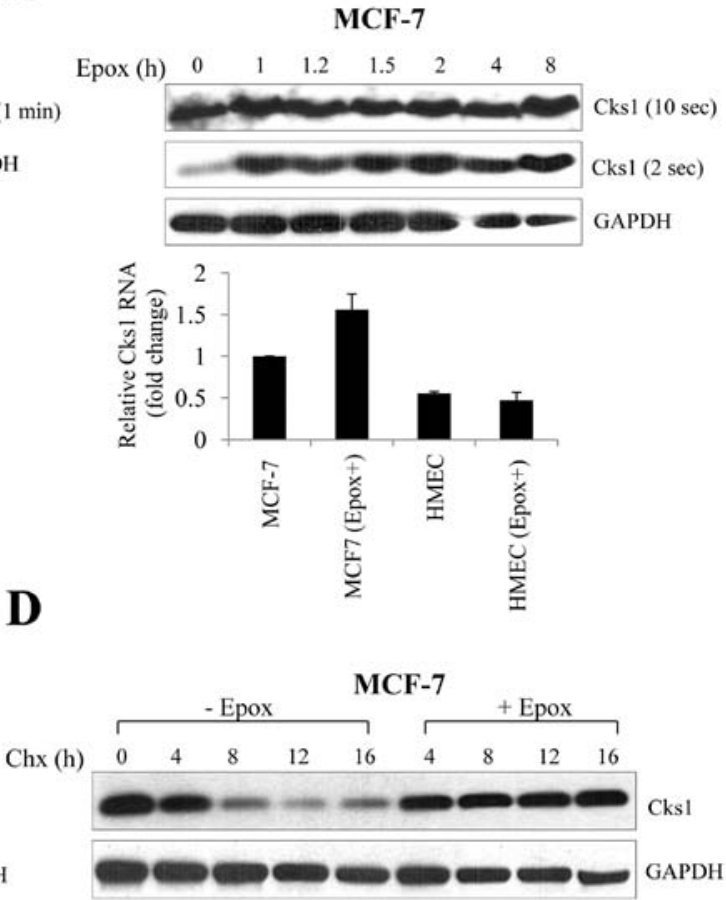

Figure 2. Cks1 protein turnover is mediated by the proteasomal degradation pathway in normal and cancer cells. (A and B) HMECs or MCF-7 cells were treated with epoximicin in parallel time-course experiments. Cells were harvested and lysed at indicated time-points and total RNA and protein was isolated. Protein lysates were analyzed by immunoblotting to determine Cks1 protein stability following proteasomal blockade. qRT-PCR was used to determine Cks1 mRNA levels. (C) PC-3 or T-47D cells were treated with epoximicin for $12 \mathrm{~h}$. Cells were harvested and protein lysates were immunoblotted to examine changes in Cks1 protein expression. (D) MCF-7 cells were either left untreated or were pretreated with epoximicin (0.5 $\mu \mathrm{M})$ for 30 min. Cells were then exposed to $\mathrm{Chx}(75 \mu \mathrm{g} / \mathrm{ml})$. Cells were harvested and lysed at indicated time-points. Protein lysates were analyzed by immunoblotting to assess changes in protein turnover of Cks1.

A

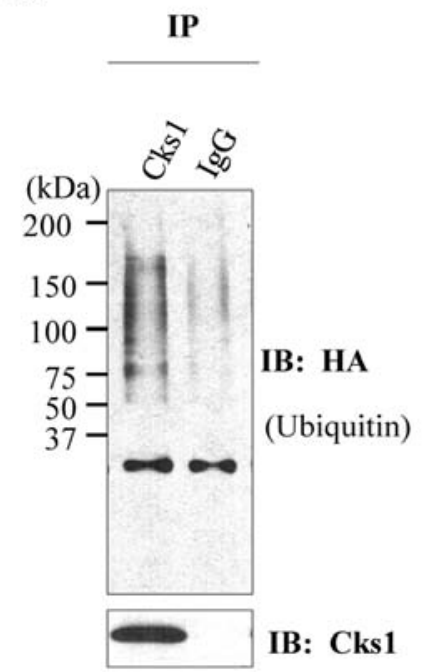

B

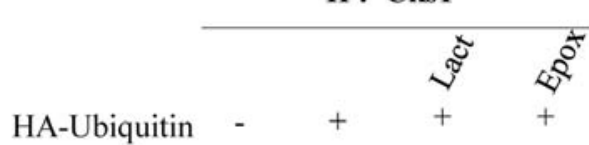

HA-Ubiq

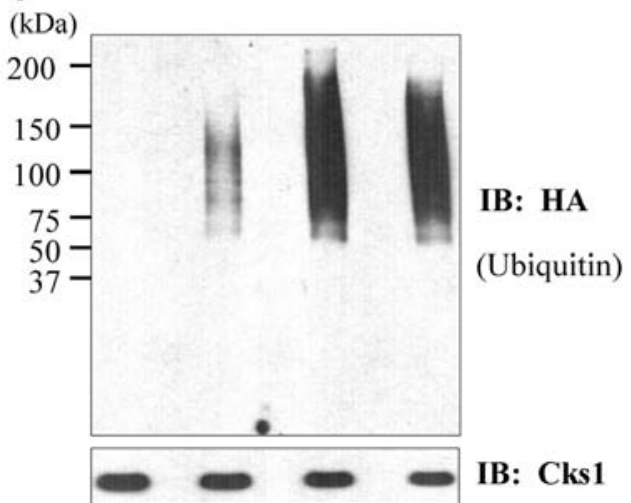

Figure 3. Proteasomal blockade upregulates ubiquitinated Cks1 in MCF-7 cells. MCF-7 cells were transiently transfected with a HA-ubiquitin plasmid. Twenty-four hours post-transfection cells were either treated with vehicle (DMSO) or the indicated proteasomal inhibitors for $8 \mathrm{~h}$. Cks1 was immunoprecipitated using a specific antibody. Immunoprecipitates were analyzed by anti-HA immunoblotting to assess changes in ubiquitination profile of Cks1. Pre-immune rabbit serum was used in control immunoprecipitations.

we transfected these cells with an expression plasmid for HA-tagged ubiquitin and assessed the ubiquitination status of immunoprecipitated Cks1 (Fig. 3). We find that Cks1-specific immunoprecipitates when probed with an anti-HA antibody reveal a large smear of polyubiquitinated Cks1 when compared to that from a control isotype-matched IgG (Fig. 3A). The proteasomal inhibitors lactacystin and epoximicin caused a marked increase in the intensity of the polyubiquitinated Cks1 
$\mathbf{A}$



B

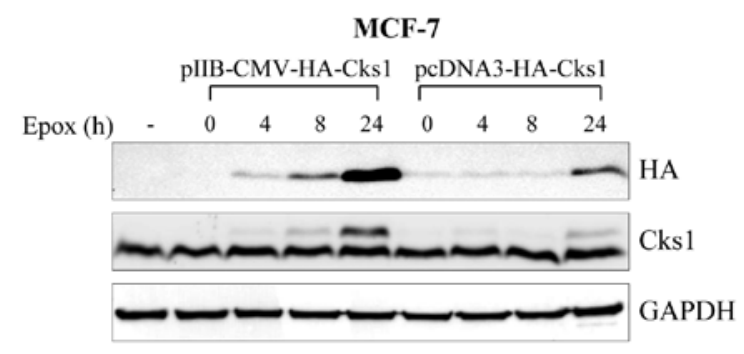

\section{C}

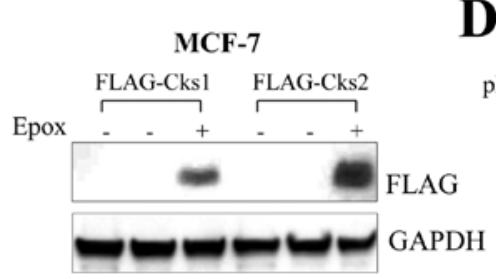

D

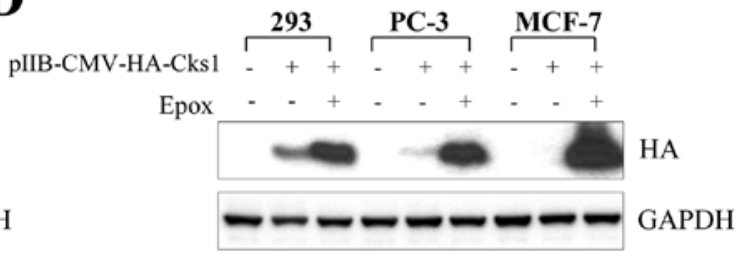

Figure 4. Transiently transfected Cks1 exhibits rapid proteasomal turnover in MCF-7 breast cancer cells. (A) MCF-7 cells were transfected with plasmids expressing either HA-Cks1 or HA-Cdc2 using identical conditions. Following transfection cells were either left untreated or treated with epoxomicin for $24 \mathrm{~h}$. Total protein and RNA was harvested from the transfected samples. Transfection efficiency was determined by using a custom TaqMan probe designed to specifically detect transfected Cks1. Protein lysates were immunoblotted with HA antibody to assess exogenous Cks1 or Cdc2 protein levels. (B) MCF-7 cells were transfected with two different plasmids expressing HA tagged Cks1 protein (pIIBMCV-HA-Cks1 and pCDNA3-HA-Cks1). Cells were then treated with epoximicin and harvested at indicated times. Protein lysates from the harvested cells were subjected to anti-HA immunoblotting to assess exogenous Cks1 expression. (C) FLAG-Cks1 and FLAG-Cks2 plasmids were transfected into MCF-7 cells as described in (A). Exogenous Cks1 or Cks2 expression was assessed by immunoblotting. (D) HEK 293 and PC-3 cells were transfected described above. Lysates were analyzed by western blotting with anti-HA antibodies.

smears indicating a reduced degradation of the polyubiquitinitated forms of the protein (Fig. 3B).

Transiently transfected Cksl is markedly unstable in multiple cell lines. To begin a systematic analysis of the residues involved in Cks1 turnover we first examined the degradation kinetics of a transiently transfected WT Cks1 in MCF-7 cells. We constructed two separate Cks1 expression plasmids driven by the strong CMV promoter-enhancer. As shown in Fig. 4A, pIIB-CMV-HA-Cks1, when transiently transfected, resulted in detectable $\mathrm{Cks} 1$ protein only in cells exposed to epoximicin for $24 \mathrm{~h}$. To confirm that this was not artifactual we examined another cDNA (HA-Cdc2) in the same vector. Our results demonstrate that unlike Cks1, HA-Cdc2 protein was amply produced even without proteasomal blockade. Data in Fig. 4A also show that HA-Cks1 mRNA expression was similar in the presence or absence of epoximicin. Taken together these results indicate that transiently expressed Cks1 is extremely unstable in MCF-7 cells. We further confirmed this finding using another CMV driven vector (pcDNA3-HA-Cks1) and again found that detectable HA-Cks1 was only found in the presence of epoximicin (Fig. 4B). Furthermore, identical results were obtained when $\mathrm{MCF}-7$ cells were transfected with the pIIB-CMV-FLAG-Cks1 vector which like the HA tagged Cks1 vector expressed detectable $\mathrm{Cks} 1$ protein only in the presence of epoximicin (Fig. 4C). This indicates that the marked instability of Cks1 was not related to a specific tag fused to its open reading frame.

To further dissect the stability of transiently expressed Cks1, we transfected PC-3 and 293 cells with the pIIB-CMVHA-Cks1 vector (Fig. 4D). Like the MCF-7 cells, PC-3 cells express detectable $\mathrm{Cks} 1$ protein only in the presence of epoximicin (Fig. 4C). Similarly, the 293 cell line, which is considered to be an efficient model for transient transfection and mammalian protein expression, also expressed only a modest level of Cks1 protein that exhibited marked stabilization following epoxomicin treatment.

We also observed that rapid proteasomal kinetics of transiently expressed Cks1 was recapitulated by the Cks2 protein, a paralog of Cks1 which bears $>81 \%$ sequence identity to the Cks1 protein (Fig. 4D). Transfection of MCF-7 cells with the FLAG-Cks2 vector revealed that similar to the transiently transfected $\mathrm{Cks} 1$ protein, the expression of $\mathrm{Cks} 2$ protein was detectable only upon epoxomicin treatment (Fig. 4D).

Collectively our data suggest that although sufficient Cks1 mRNA expression can be achieved from transiently 
A
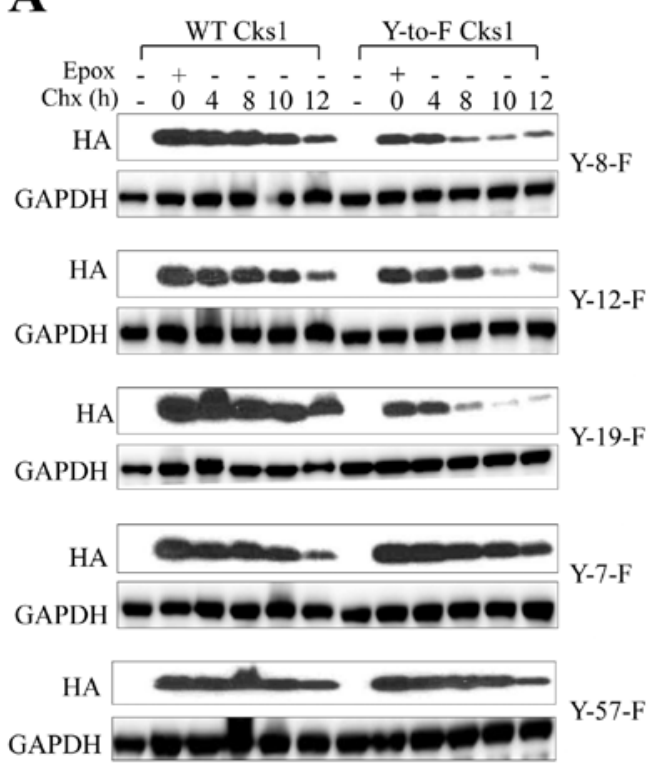

B

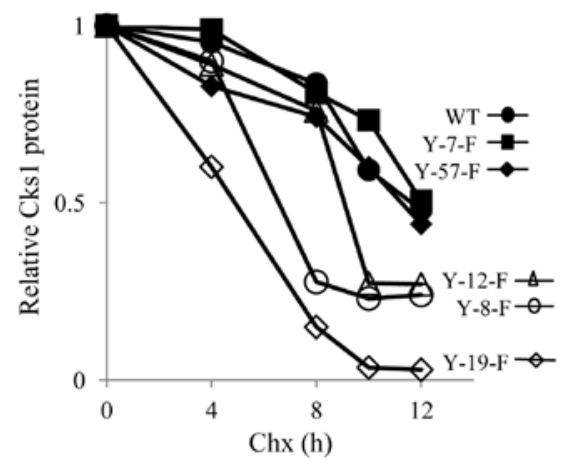

Figure 5. Effect of replacing specific tyrosines with phenylalanine on proteasomal turnover of Cks1. (A) MCF-7 cells were transfected with either WT or mutant Y-F constructs of Cksl. Following transfection cells were treated with epoximicin for $24 \mathrm{~h}$. Twenty-four hours post epoximicin treatment cells were treated to Chx to stop de novo protein synthesis. Cells were harvested and lysed at indicated times. Protein lysates were immunoblotted with anti-HA antibodies to compare the degradation of WT and mutant protein. (B) Densitometric analysis of western blots in (A) comparing degradation rate of WT and Y-F Cks1 proteins after Chx addition. The analysis represents densitometric changes measured by NIH Image J of HA and GAPDH with time, and is representative of three independent experiments.

A

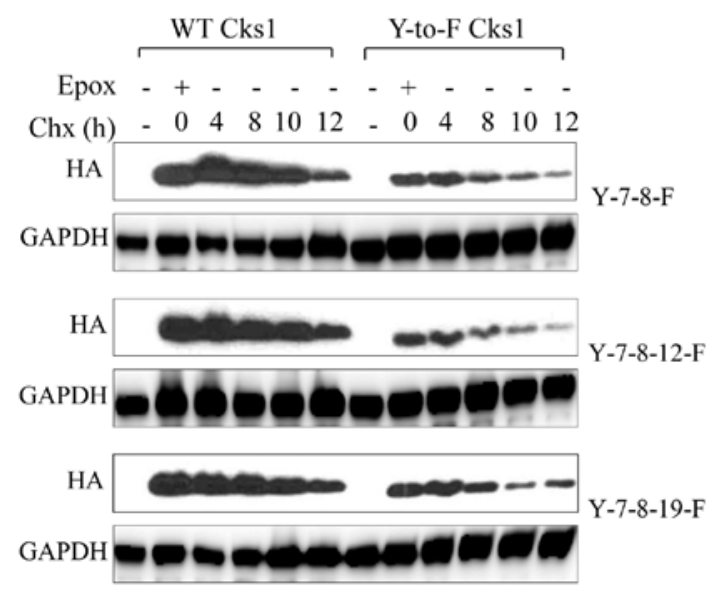

B

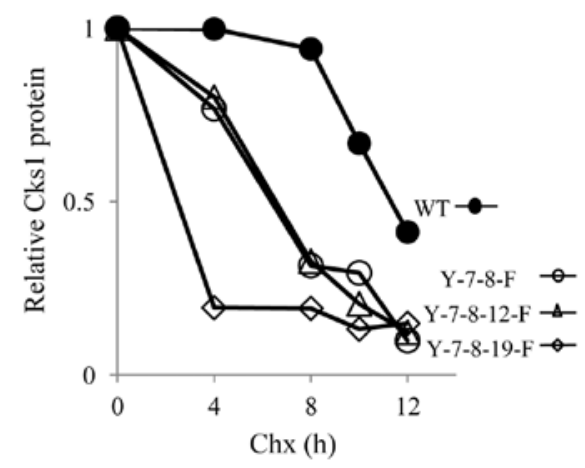

Figure 6. Effect of combined substitution mutations altering tyrosines 7, 8, 12 or 19 on proteasomal turnover of Cks1. (A) MCF-7 cells were transfected with either WT or indicated Y-F constructs of Cks1. Chx chase experiments (as described in Fig. 5) were carried out to compare degradation rates of WT and combination Y-F mutants of Cks1 protein. Cells were harvested and lysed at indicated times and lysates were immunoblotted with anti-HA antibodies. (B) Densitometric analysis of western blots comparing degradation rate of WT and Y-F Cks1 proteins. The analysis is representative of three independent experiments.

transfected CMV-driven Cks1 expression plasmids, its protein (and also that of Cks2) exhibits rapid proteasomal turnover in MCF-7 carcinoma cells.

Effect of specific $Y$-F substitutions on proteasomal degradation of Cksl in MCF-7 cells. To identify structural determinants that are critical for $\mathrm{Cks1}$ protein stability we introduced specific Y-F substitutions into its primary sequence and assessed their effects on the kinetics of degradation as compared to WT Cks1 (Fig. 5). We transiently transfected WT and Y-F Cks1 mutants into MCF-7 cells, followed by epoximicin treatment for $24 \mathrm{~h}$. The cells were then washed and protein turnover was followed after addition of $\mathrm{Chx}$ to inhibit further translation. As shown in Fig. 5, substitution of Y residues 8, 12 and 19 with F significantly increased the turnover of exogenous Cks1 protein (Fig. 5). On the other hand the turnover kinetics of Y57F and Y7F were nearly identical to that of the WT Cks1 (Fig. 5). We further observed that proteasomal degradation was even more accelerated in the case of the combination with mutants Y-7-8-F, Y-7-8-12-F and Y-7-8-19-F (Fig. 6). All of these muta- 


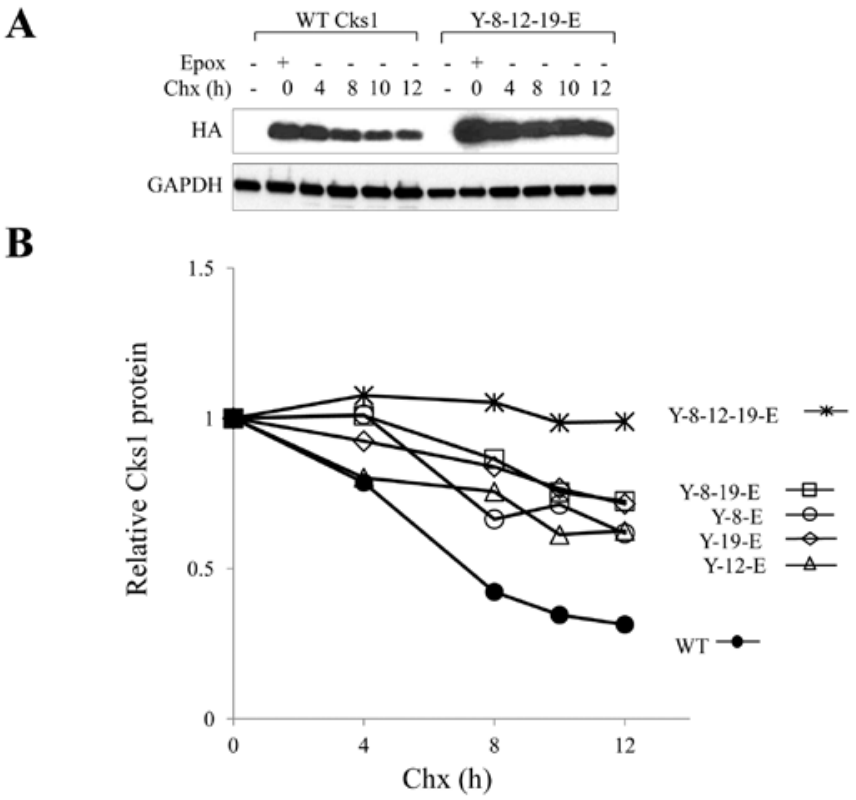

Figure 7. Effect of Y-E substitutions on the proteasomal turnover of Cks1. (A) MCF-7 cells were transfected with either WT or the Y-8,12,19-E constructs of Cks1. Chx degradation chase experiments were carried out as described in Fig. 5. Cells were harvested and lysed at indicated times and lysates were immunoblotted with anti-HA antibodies. (B) The graph represents densitometric analysis comparing degradation rates of WT and different Y-E Cks1 molecules and is representative of three independent experiments.

tions markedly increased the rate of degradation, depleting the protein within 8-10 h following Chx treatment (Fig. 6). In sum, our results indicate that $\mathrm{Y}$ residues 8, 12 and 19 in Cks1 are critical for its proteasomal turnover.

Effect of $Y$-E substitutions on proteasomal degradation of Cksl in MCF-7 cells. Y residues within a protein can, in principle, regulate stability through multiple mechanisms. For instance phosphorylation of Y residues can create phosphodegrons allowing the recognition of the substrate protein by a specific ubiquitin ligase which in turn can append ubiquitin molecules to the protein and target it for proteasomal degradation (32). Our results with specific phospho-defective Y-F Cks1 substitutions prompted us to investigate the effects of potential phospho-mimicking ones at the same residues. We introduced Y-E substitutions on residues 8,12 and 19 both individually and in combination. Like the WT and Y-F Cks1 protein, Y-E mutant proteins were detectable only upon epoximicin treatment. However, in contrast to the Y-F mutations, Y-E mutations at residues 8, 12 and 19 substantially slowed down the turnover of Cks1 following Chx addition (Fig. 7 and data not shown). Furthermore, the rate of degradation of Cks1 protein bearing the triple Y-E substitution on residues 8, 12 and 19 was markedly slower than that of Cks1 protein bearing single Y-E substitutions on these residues (Fig. 7B).

Effect of $K-R$ substitutions in $C k s 1$ on its proteasomal degradation in MCF-7 cells. The role of specific $\mathrm{K}$ residues, the $\varepsilon$-amino group of which serves as the most common ubiquitin attachment site, has not been elucidated in the context of Cks1. $\mathrm{Cks} 1$ has nine $\mathrm{K}$ residues each of which could potentially serve as a ubiquitin attachment site. We individually mutated each one of these $\mathrm{K}$ residues of Cks1 to an arginine (R). We also simultaneously mutated all four terminal $\mathrm{K}$ residues of Cks1 to R. K-R substitution retains the positive charge of the amino acid but abrogates ubiquitination. Like the Y-F and Y-E mutants, all K-R mutants of Cks1 expressed detectable amount of Cks1 protein only upon epoxomicin treatment (Fig. 8). We compared the degradation kinetics of K-R mutants of Cks1 with that of WT Cks1. We found that K-R substitutions at residues 4 and 34, and to a larger extent in the more conserved lysine residues 26 and 30, greatly stabilized Cks1. On the other hand K-R substitutions at residues 11, 75, 76 did not markedly affect Cks1 stability (Fig. 8). Strikingly, replacing the terminal K79 residue with $\mathrm{R}$ greatly increased the turnover of Cks1 (Fig. 8). This was further corroborated with the K-R combination mutant where Rs were introduced in place of all four $\mathrm{K}$ residues in the C-terminus (Fig. 8).
A

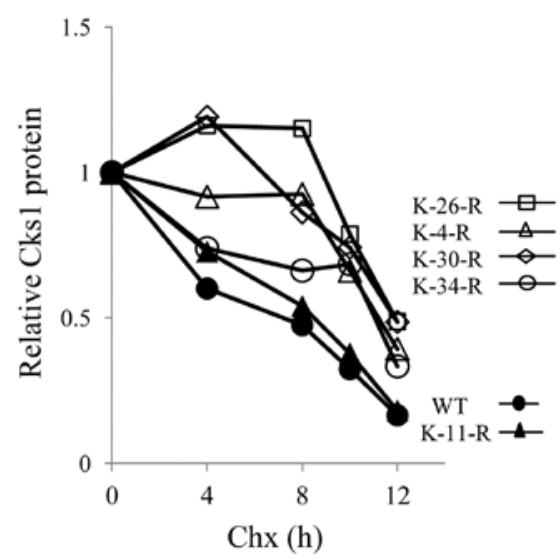

B

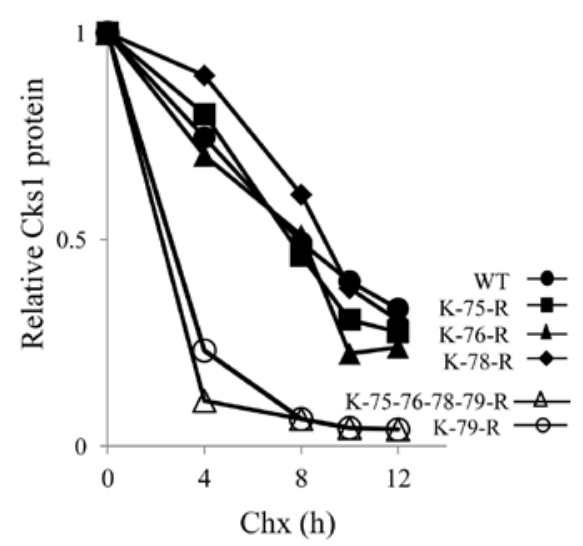

Figure 8. Effect of K-R mutations on on the proteasomal turnover of Cks1. (A) MCF-7 cells were transfected with the indicated constructs of Cks1. Chx degradation chase experiments were carried out as described in the legend to Fig. 5. Cells were harvested and lysed at indicated times and lysates were immunoblotted with anti-HA antibodies. (B) The graph represents densitometric analysis, comparing degradation rates of WT and K-R Cks1 protein and is representative of three independent experiments. 
Table I. Gene expression of WT and Y-to-F HA-Cks1 in MCF-7 cells.

\begin{tabular}{|c|c|c|c|c|c|}
\hline \multirow[b]{3}{*}{ Transfection } & \multicolumn{5}{|c|}{ Average $\mathrm{C}(\mathrm{t})$ values } \\
\hline & \multirow{2}{*}{$\frac{\text { TaqMan probe }}{\text { Treatment }}$} & \multicolumn{2}{|c|}{ HA-Cks1 } & \multicolumn{2}{|c|}{ GAPDH } \\
\hline & & No epox & Epox & No epox & Epox \\
\hline No transfection & & $\mathrm{N} / \mathrm{A}$ & N/A & $19.92 \pm 0.09$ & $18.01 \pm 0.16$ \\
\hline WT & & $20.41 \pm 0.22$ & $19.60 \pm 0.11$ & $18.36 \pm 0.24$ & $20.53 \pm 0.05$ \\
\hline Y-7-F & & $17.47 \pm 0.24$ & $16.73 \pm 0.10$ & $18.69 \pm 0.40$ & $20.33 \pm 0.69$ \\
\hline Y-8-F & & $18.02 \pm 0.03$ & $15.52 \pm 0.31$ & $19.90 \pm 0.35$ & $19.49 \pm 0.18$ \\
\hline Y-7-8-F & & $18.20 \pm 0.15$ & $16.31 \pm 0.09$ & $19.11 \pm 0.20$ & $19.78 \pm 0.04$ \\
\hline Y-12-F & & $18.72 \pm 0.17$ & $16.93 \pm 0.22$ & $18.90 \pm 0.41$ & $20.15 \pm 0.25$ \\
\hline Y-7-8-12-F & & $16.27 \pm 0.19$ & $15.15 \pm 0.07$ & $18.70 \pm 0.61$ & $19.3 \pm 0.15$ \\
\hline Y-19-F & & $18.41 \pm 0.11$ & $16.92 \pm 0.18$ & $19.98 \pm 0.61$ & $19.95 \pm 0.42$ \\
\hline Y-7-8-19-F & & $18.87 \pm 0.27$ & $19.14 \pm 0.16$ & $19.9 \pm 0.37$ & $19.23 \pm 0.31$ \\
\hline Y-57-F & & $18.03 \pm 0.07$ & $18.92 \pm 0.17$ & $19.79 \pm 0.59$ & $19.52 \pm 0.52$ \\
\hline
\end{tabular}

WT, wild-type; Y, tyrosine; F, phenylalanine; Cks1, cyclin kinase subunit 1; C(t), threshold cycle; GAPDH, glyceraldehyde 3-phosphate dehydrogenase.

Table II. Gene expression of WT and K-to-R HA-Cks1 in MCF-7 cells.

\begin{tabular}{|c|c|c|c|c|c|}
\hline \multirow[b]{3}{*}{ Transfection } & \multicolumn{5}{|c|}{ Average $\mathrm{C}(\mathrm{t})$ values } \\
\hline & \multirow{2}{*}{$\frac{\text { TaqMan probe }}{\text { Treatment }}$} & \multicolumn{2}{|c|}{ HA-Cks1 } & \multicolumn{2}{|c|}{ GAPDH } \\
\hline & & No epox & Epox & No epox & Epox \\
\hline No transfection & & N/A & N/A & $22.42 \pm 0.13$ & $21.91 \pm 0.21$ \\
\hline WT & & $21.07 \pm 0.97$ & $21.94 \pm 0.82$ & $22.28 \pm 0.71$ & $21.97 \pm 0.21$ \\
\hline $\mathrm{K}-4-\mathrm{R}$ & & $19.08 \pm 0.93$ & $18.11 \pm 1.78$ & $21.24 \pm 0.47$ & $22.87 \pm 0.30$ \\
\hline $\mathrm{K}-11-\mathrm{R}$ & & $21.65 \pm 0.74$ & $21.47 \pm 0.79$ & $22.61 \pm 0.23$ & $22.41 \pm 0.29$ \\
\hline K-26-R & & $19.09 \pm 0.65$ & $18.50 \pm 0.17$ & $22.60 \pm 0.22$ & $23.25 \pm 0.28$ \\
\hline $\mathrm{K}-30-\mathrm{R}$ & & $21.15 \pm 0.78$ & $18.47 \pm 0.17$ & $22.71 \pm 0.18$ & $22.79 \pm 0.03$ \\
\hline $\mathrm{K}-34-\mathrm{R}$ & & $19.93 \pm 0.44$ & $19.07 \pm 0.79$ & $22.03 \pm 0.11$ & $23.50 \pm 0.11$ \\
\hline $\mathrm{K}-75-\mathrm{R}$ & & $21.16 \pm 0.43$ & $20.06 \pm 0.75$ & $23.20 \pm 0.15$ & $23.70 \pm 0.05$ \\
\hline $\mathrm{K}-76-\mathrm{R}$ & & $21.97 \pm 0.35$ & $19.86 \pm 0.86$ & $22.40 \pm 0.28$ & $23.11 \pm 0.08$ \\
\hline $\mathrm{K}-78-\mathrm{R}$ & & $21.86 \pm 0.54$ & $20.40 \pm 0.78$ & $23.16 \pm 0.23$ & $22.91 \pm 0.15$ \\
\hline $\mathrm{K}-79-\mathrm{R}$ & & $21.64 \pm 0.70$ & $20.36 \pm 0.77$ & $22.38 \pm 0.27$ & $23.83 \pm 0.19$ \\
\hline K-75-76-78-79-R & & $20.88 \pm 0.62$ & $20.15 \pm 0.83$ & $23.59 \pm 0.17$ & $23.57 \pm 0.25$ \\
\hline
\end{tabular}

WT, wild-type; K, lysine; R, arginine; Cks1, cyclin kinase subunit 1; C(t), threshold cycle; GAPDH, glyceraldehyde 3-phosphate dehydrogenase.

Transcription of transiently transfected mutant Cksl in MCF-7 cells is not impaired. To demonstrate that impaired transcription of mutant Cks1 cDNAs, or differences in transfection efficiency, could not account for the differences in the turnover exhibited by these proteins as compared to WT Cks1, we measured their mRNA levels in the transfected MCF-7 cells, both in the presence and absence of epoximicin (Tables I and II). We employed a custom TaqMan probe targeted to detect only the transfected HA-Cks1 transcript. The TaqMan probe was designed to detect the WT and mutant HA-Cks1 transcripts while excluding hybridization to any region of Cks1 cDNA sequence that contains Y-F or K-R substitutions. No amplification was detected in the untransfected samples confirming the specificity of the probe (Tables I and II). Furthermore, no significant differences in $\mathrm{C}(\mathrm{t})$ values were found between WT and any of the mutant Cks1 cDNA samples obtained from total mRNA harvested from the transfected cells (Tables I and II). Similarly to the WT Cks1 described in Fig. 4, 
A

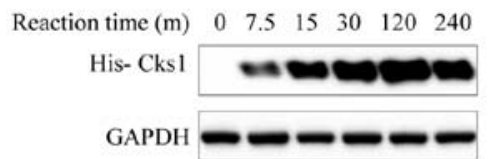

C

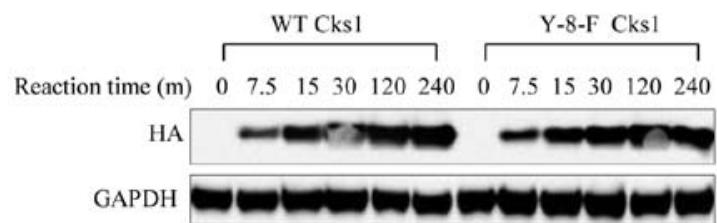

B

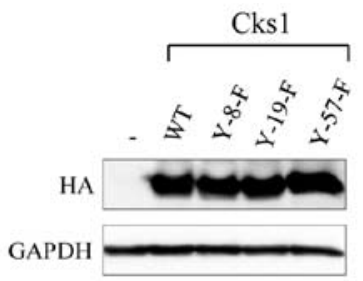

D

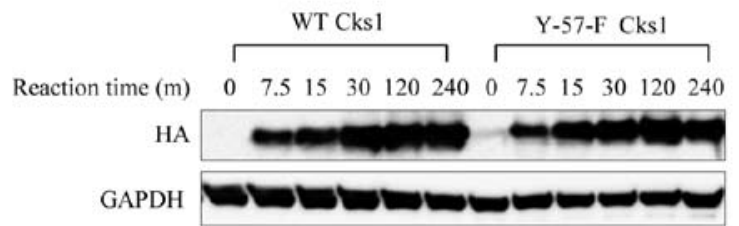

Figure 9. Coupled in vitro expression of Cks1 protein. (A) WT Cks1 coding sequence was ligated into the pT7CFE-His vector which drives in vitro transcription by a T7 promoter. A HeLa lysate based system (Thermo Scientific) with accessory protein and energy source was used to drive in vitro translation of Cks1 protein. (B-D) WT HA-Cks1 and Y-F mutants of Cks1 were cloned into the vector as described above and coupled transcription-translation reactions were set up. (B) Relative protein synthesis of WT and Y-F Cks1 protein was compared after a 1-h reaction. (C and D) Coupled transcription-translation reactions were run for the indicated times.

expression was not altered after epoximicin treatment in the transfected Cks1 mutants (Tables I and II). These results allow us to conclude that the differences in turnover observed for mutants with point mutations introduced into their sequence were not the result of defects in their transcription.

Translation of Cksl proteins with Y-F substitutions is not impaired in a cell-free system. To assess if the inherent instability of the transfected Y-F mutant HA-Cks1 molecules is due to defects in their translation, we employed an in vitro system for mammalian protein expression. This system allows robust in vitro translation of protein derived from message under control of a T7 promoter in HeLa cell lysates. Aliquots were taken at regular intervals after start of reaction and electrophoresed and subjected to immunoblotting (Fig. 9). We found that abundant levels of WT and the three mutant Cks1 molecules Y8F, Y19F and Y57F were expressed within the first 10 min of the in vitro reaction (Fig. 9). Cks1 protein translation in vitro was time-dependent and was independent of mutation within the Cks1. We found similar rates of translation with the other mutants as well (data not shown). The synthesis of WT Cks1 and all the mutants achieved almost full saturation after first hour of the reaction indicating that they were not impaired in translation (Fig. 9C and D and data not shown).

\section{Discussion}

Previous gene expression studies have identified Cks1 as one of the most commonly upregulated transcripts in both human and mouse mammary cancer as compared to normal epithelial organoids obtained from reduction mammoplasty specimens, or normal mouse mammary epithelium, respectively (33). While one mode of $\mathrm{Cks1}$ regulation is transcriptional, it also appears to be regulated at the level of the protein. Whole transcriptome sequencing of normal breast epithelium has revealed that $\mathrm{Cks1}$ is transcribed therein at reasonably high levels (14), although its protein level in this tissue as well as other normal human tissues is nearly undetectable (Fig. 1C). Studies from our laboratory have also revealed that that normal mouse or rat tissues exhibit very low levels of Cks1 protein, whereas its levels were very high in mammary tumors excised from murine transgenic models of mammary tumorigenesis (erbB2, c-myc and polyoma middle-T transgenic mice) and also in a carcinogeninitiated rat mammary tumor (7). Previous studies have also demonstrated Cks1 is polyubiquitinated and degraded by the proteasome $(16,17)$. In agreement with these studies we also observed stabilization of Cks1 protein in normal HMECs, as well as MCF-7, PC-3 and T47D cancer cells upon epoximicin treatment (Fig. 2). Together, this allowed us to hypothesize that although Cks1 mRNA is induced in cancers, a major part of endogenous Cks1 regulation, both in normal as well as in tumor cells, is at the level of the protein turnover.

In this report we have also demonstrated that transient transfection of WT Cks1 into either MCF-7 breast carcinoma, PC-3 prostate carcinoma or even 293 embryonic kidney cells resulted in detectable Cks1 protein only upon proteasomal blockade (Fig. 4). Similar to our findings, Hattori et al had also shown that transiently transfected Cks1 was stabilized by the proteasomal inhibitor MG-132 (16). Furthermore, in agreement with these studies we demonstrated that endogenous polyubiquitinated Cks1 accumulates upon proteasomal blockade (Fig. 3). Collectively, the evidence supports the notion that Cks1 is extremely unstable not only in normal cells, but also in cancer cells.

To elucidate the mechanisms that lead to Cks1 protein turnover it is necessary to identify those elements in its primary amino acid sequence that bestow instability, or conversely reduce its degradative potential. High throughput proteomic studies have indicated that Cks1 is post-translationally modified at multiple residues (23-26,29,30). Particularly striking are recurring examples of Y-phosphorylation (23-26). Cks1 contains five conserved $\mathrm{Y}$ residues. Both $\mathrm{Y} 7$ and $\mathrm{Y} 8$ have been demonstrated to be phosphorylated in HMEC $24 \mathrm{H}$, a carcinogen immortalized human mammary epithelial line 
transfected with Her2. These residues, as well as Y12 have also been shown to be phosphorylated in cancer lines such as Jurkat (T-cell leukemia) and HeLa (cervical cell carcinoma). Y19 was also found to be phosphorylated in cells expressing the oncogenic fusion protein nucleophosmin-anaplastic lymphoma kinase (NPM-ALK) (25). As a first attempt to identify the residues in Cks1 that impart stability or ones that confer susceptibility to degradation, we resorted to transfections in MCF-7 cells with specific phosphodefective HA-Cks1 expression plasmids containing Y-F substitutions at each of these residues. Whereas the mutants Y7F and Y57F were as stable as WT Cks1, altering Y8, Y12 and Y19 to F made the protein considerably less stable (Fig. 5). The observation that the combined Y-F mutations at 8, 12 and 19 exacerbates the proteasomal degradation of $\mathrm{Cks1}$ as compared to single $\mathrm{Y}-\mathrm{F}$ substitutions at each of these residue suggests that signaling mechanisms that induce multisite phosphorylation cascades could be critical for Cks1 protein stability (Fig. 6). The idea that phosphorylation at these residues could be responsible for regulating Cks1 stability is further strengthened by the finding that phosphomimicking Y-E substitutions at these specific residues markedly reduced the rate of Cksl proteasomal turnover with respect to WT (Fig. 7).

Whether Y-phosphorylation can regulate Cks1 turnover and the mechanistic details of such potential regulation are not clear and will require further investigation. It is important to note that $\mathrm{Cks} 2$, which bears high sequence identity to Cks1 and has six $\mathrm{Y}$ residues, five of which are at positions identical to that in Cks1, also expressed detectable levels of protein only upon epoximicin treatment. Collectively, this could suggest that structural features surrounding the Y residues within Cks family of proteins could facilitate interactions with proteins that recognize phosphotyrosines which in turn initiate protein turnover regulatory signaling mechanisms. In general, classical interaction domains for phosphotyrosine modules are the Src homology 2 (SH2) and the phosphotyrosine binding (PTB) domains (34). The human genome contains $\sim 120$ different $\mathrm{SH} 2$ domains in 110 different proteins and $\sim 56$ different PTB domains (34). In the case of $\mathrm{Cks} 1$, the $\mathrm{Y} 7$ and $\mathrm{Y} 8$ residues are encompassed within the sequence IYYSD which is a potential SH2 binding sequence (35). Also, Y19 in Cks1 which has experimentally been confirmed to be phosphorylated in cells expressing the NPM-ALK tyrosine kinase is part of the sequence EEFEYRHV that is highly similar to motifs within receptors for EGF, PDGF, FGF and insulin (36). Further investigation of the phosphotyrosine interactome at these sequences will be needed to elucidate how these sequences could regulate the turnover of Cks1.

Proteomic studies have also indicated that Cks1 is ubiquitinated at K4 and acetylated at K11 (29). Cks1 has nine K residues of which four, K11, K26, K30 and K34 are conserved across multiple species. Interestingly, the four terminal $\mathrm{K}$ residues $\mathrm{K} 75$, K76, K78 and K79 form part of a polybasic structural motif found in the C-termini of small GTPases that control diverse signaling and transport processes (37). Whereas R substitutions at residues $\mathrm{K} 4, \mathrm{~K} 26, \mathrm{~K} 30$ and $\mathrm{K} 34$ stabilized Cks1, mutations at residues 11,75 or 76 had negligible effects on protein stability. In contrast, replacing the last residue in Cks1 (K79) with R dramatically destabilized the protein. In fact mutations in neighboring 3 terminal lysine residues, which by themselves have no effect on Cks1 protein stability, did not alter the destabilizing effect of the K-79-R mutation. Although any one or more of these lysine residues could potentially serve as a ubiquitin attachment site, and mutating one or more of these could impair ubiquitination and alter degradation of Cks1, abrogation of none of the $\mathrm{K}$ sites individually, nor in combinations, led to stabilization in the absence of epoximicin. This suggests that Cks1 could also be subject to ubiquitination at the amino terminus and/or other redundant ubiquitination independent modes of degradation.

In conclusion, our study for the first time attempts at a systematic analysis of the primary sequence of Cks1 in an effort to identify structural elements necessary for Cks1 protein stability. This has led to the identification of three specific $Y$ residues Y8, Y12 and Y19 that are important for its stability. We have also demonstrated that the terminal K residue, K79 is essential for its stability. Our previous studies which demonstrated transient induction of Cks1 protein following treatment with media containing insulin, EGF and hydrocortisone in HMECs, where the basal levels are undetectable, suggest stringent regulation of its turnover in normal cells (4). Importantly, the molecular mechanisms that lead to marked differences in Cks1 protein expression in normal tissues and cancer cells have yet to be characterized. Like HMECs, Cks1 protein is markedly stabilized in MCF-7 cancer cells upon epoximicin treatment. However, owing to its high constitutive expression, Cks1 stabilization following proteasomal blockade was less apparent in cancer cells. These observations suggest that regulatory pathways critical for timely degradation of $\mathrm{Cks} 1$ in normal breast cells is perturbed in cancer cells. Further elucidation of these pathways will likely lead to targeted therapeutic strategies designed to induce Cks1 depletion in cancer cells.

\section{Acknowledgements}

This study was supported in part by a grant from the Komen Breast Cancer Foundation (to J.V.T.). V.K. received support from the Alabama Innovation Fund.

\section{References}

1. Khattar V and Thottassery JV: Cks1: structure, emerging roles and implications in multiple cancers. J Cancer Ther 4: 1341-1354, 2013.

2. Ganoth D, Bornstein G, Ko TK, Larsen B, Tyers M, Pagano M and Hershko A: The cell-cycle regulatory protein Cks1 is required for $\mathrm{SCF}(\mathrm{Skp} 2)$-mediated ubiquitinylation of $\mathrm{p} 27$. Nat Cell Biol 3: 321-324, 2001.

3. Spruck C, Strohmaier H, Watson M, et al: A CDK-independent function of mammalian Cks1: targeting of $\operatorname{SCF}(\operatorname{Skp} 2)$ to the CDK inhibitor p27 ${ }^{\mathrm{Kip} 1}$. Mol Cell 7: 639-650, 2001.

4. Westbrook L, Manuvakhova M, Kern FG, Estes NR, Ramanathan HN and Thottassery JV: Cks1 regulates cdk1 expression: a novel role during mitotic entry in breast cancer cells. Cancer Res 67: 11393-11401, 2007.

5. Hoellein A, Graf S, Bassermann F, et al: Cks1 promotion of $\mathrm{S}$ phase entry and proliferation is independent of $\mathrm{p} 27^{\mathrm{Kipl}}$ suppression. Mol Cell Biol 32: 2416-2427, 2012.

6. Liberal V, Martinsson-Ahlzen HS, Liberal J, Spruck CH, Widschwendter M, McGowan CH and Reed SI: Cyclin-dependent kinase subunit (Cks) 1 or Cks2 overexpression overrides the DNA damage response barrier triggered by activated oncoproteins. Proc Natl Acad Sci USA 109: 2754-2759, 2012.

7. Westbrook L, Ramanathan HN, Isayeva T, et al: High Cks1 expression in transgenic and carcinogen-initiated mammary tumors is not always accompanied by reduction in $\mathrm{p} 27^{\mathrm{Kip} 1}$. Int $\mathrm{J}$ Oncol 34: 1425-1431, 2009. 
8. Slotky M, Shapira M,Ben-Izhak O,Linn S, Futerman B, Tsalic M and Hershko DD: The expression of the ubiquitin ligase subunit Cks1 in human breast cancer. Breast Cancer Res 7: R737-R744, 2005.

9. Shapira M, Ben-Izhak O, Slotky M, Goldin O, Lahav-Baratz S and Hershko DD: Expression of the ubiquitin ligase subunit cyclin kinase subunit 1 and its relationship to S-phase kinase protein 2 and $\mathrm{p} 27^{\mathrm{Kipl}}$ in prostate cancer. J Urol 176: 2285-2289, 2006.

10. Lee SW, Kang SB, Lee DS and Lee JU: Akt and Cks1 are related with lymph node metastasis in gastric adenocarcinoma. Hepatogastroenterology 60: 932-937, 2013.

11. Nagler RM, Ben-Izhak O, Ostrovsky D, Golz A and Hershko DD: The expression and prognostic significance of Cks1 in salivary cancer. Cancer Invest 27: 512-520, 2009.

12. Calvisi DF, Ladu S, Pinna F, et al: SKP2 and CKS1 promote degradation of cell cycle regulators and are associated with hepatocellular carcinoma prognosis. Gastroenterology 137: 1816-1826, 2009

13. Chang H, Jiang N, Jiang H, Saha MN, Qi C, Xu W and Reece D CKS1B nuclear expression is inversely correlated with $\mathrm{p} 27^{\mathrm{Kip}}$ expression and is predictive of an adverse survival in patients with multiple myeloma. Haematologica 95: 1542-1547, 2010.

14. Pardo I, Lillemoe HA, Blosser RJ, et al: Next-generation transcriptome sequencing of the premenopausal breast epithelium using specimens from a normal human breast tissue bank. Breast Cancer Res 16: R26, 2014.

15. Hershko A and Ciechanover A: The ubiquitin system for protein degradation. Annu Rev Biochem 61: 761-807, 1992.

16. Hattori T, Kitagawa K, Uchida C, Oda T and Kitagawa M: Cks1 is degraded via the ubiquitin-proteasome pathway in a cell cycledependent manner. Genes Cells 8: 889-896, 2003.

17. Bashir T, Dorrello NV, Amador V, Guardavaccaro D and Pagano M: Control of the SCF (Skp2-Cks1) ubiquitin ligase by the APC/C (Cdh1) ubiquitin ligase. Nature 428: 190-193, 2004.

18. Hunter T: The age of crosstalk: phosphorylation, ubiquitination, and beyond. Mol Cell 28: 730-738, 2007.

19. Ungureanu D, Saharinen P, Junttila I, Hilton DJ and Silvennoinen O: Regulation of Jak2 through the ubiquitinproteasome pathway involves phosphorylation of Jak2 on Y1007 and interaction with SOCS-1. Mol Cell Biol 22: 3316 3326, 2002.

20. Ali S, Nouhi Z, Chughtai N and Ali S: SHP-2 regulates SOCS-1mediated Janus kinase-2 ubiquitination/degradation downstream of the prolactin receptor. J Biol Chem 278: 52021-52031, 2003

21. He G, Zhang YW, Lee JH, et al: AMP-activated protein kinase induces $\mathrm{p} 53$ by phosphorylating MDMX and inhibiting its activity. Mol Cell Biol 34: 148-157, 2014.

22. Nalavadi VC, Muddashetty RS, Gross C and Bassell GJ Dephosphorylation-induced ubiquitination and degradation of FMRP in dendrites: a role in immediate early mGluR-stimulated translation. J Neurosci 32: 2582-2587, 2012.
23. Wolf-Yadlin A, Kumar N, Zhang Y, et al: Effects of HER2 overexpression on cell signaling networks governing proliferation and migration. Mol Syst Biol 2: 54, 2006.

24. Hornbeck PV, Kornhauser JM, Tkachev S, Zhang B, Skrzypek E, Murray B, Latham V and Sullivan M: PhosphoSitePlus: a comprehensive resource for investigating the structure and function of experimentally determined post-translational modifications in man and mouse. Nucleic Acids Res 40: D261-D270, 2012

25. Wu F, Wang P, Young LC, Lai R and Li L: Proteome-wide identification of novel binding partners to the oncogenic fusion gene protein, NPM-ALK, using tandem affinity purification and mass spectrometry. Am J Pathol 174: 361-370, 2009.

26. Olsen JV, Vermeulen M, Santamaria A, et al: Quantitative phosphoproteomics reveals widespread full phosphorylation site occupancy during mitosis. Sci Signal 3: ra3, 2010.

27. Shirayama M, Soto MC, Ishidate T, et al: The conserved kinases CDK-1, GSK-3, KIN-19, and MBK-2 promote OMA-1 destruction to regulate the oocyte-to-embryo transition in $C$. elegans. Curr Biol 16: 47-55, 2006.

28. Arvai AS, Bourne Y, Hickey MJ and Tainer JA: Crystal structure of the human cell cycle protein $\mathrm{CksHs}$ : single domain fold with similarity to kinase N-lobe domain. J Mol Biol 249: 835-842, 1995.

29. Choudhary C, Kumar C, Gnad F, et al: Lysine acetylation targets protein complexes and co-regulates major cellular functions. Science 325: 834-840, 2009.

30. Kim W, Bennett EJ, Huttlin EL, et al: Systematic and quantitative assessment of the ubiquitin-modified proteome. Mol Cell 44: 325-340, 2011

31. Pfaffl MW: A new mathematical model for relative quantification in real-time RT-PCR. Nucleic Acids Res 29: e45, 2001.

32. Holt LJ: Regulatory modules: coupling protein stability to phosphoregulation during cell division. FEBS Lett 586: 2773-2777, 2012.

33. Hu Y, Sun H, Drake J, et al: From mice to humans: identification of commonly deregulated genes in mammary cancer via comparative SAGE studies. Cancer Res 64: 7748-7755, 2004.

34. Kaneko T, Joshi R, Feller SM and Li SS: Phosphotyrosine recognition domains: the typical, the atypical and the versatile. Cell Commun Signal 10: 32, 2012.

35. Burshtyn DN, Yang W, Yi T and Long EO: A novel phosphotyrosine motif with a critical amino acid at position -2 for the $\mathrm{SH} 2$ domain-mediated activation of the tyrosine phosphatase SHP-1. J Biol Chem 272: 13066-13072, 1997.

36. Songyang Z: Recognition and regulation of primary-sequence motifs by signaling modular domains. Prog Biophys Mol Biol 71: 359-372, 1999.

37. Heo WD, Inoue T, Park WS, Kim ML, Park BO, Wandless TJ and Meyer T: $\mathrm{PI}(3,4,5) \mathrm{P} 3$ and $\mathrm{PI}(4,5) \mathrm{P} 2$ lipids target proteins with polybasic clusters to the plasma membrane. Science 314 : $1458-1461,2006$ 